\title{
Analysis on Influencing Factors and Countermeasures for College Students' Network Entertainment
}

\author{
Xiaohong Liu ${ }^{1}$, Lisi Wang ${ }^{2} \&$ Qiong Yang ${ }^{3}$ \\ ${ }^{1}$ Educational Technology Center, Changchun University of Science and Technology, Changchun, China \\ ${ }^{2}$ School of Foreign Languages, Changchun University of Science and Technology, Changchun, China \\ ${ }^{3}$ Teaching Research Department, Changchun University of Science and Technology, Changchun, China \\ Correspondence: Xiaohong Liu, Educational Technology Center, Changchun University of Science and \\ Technology, Changchun 130022, China. Tel: 86-189-4366-0011. E-mail: 853278162@qq.com
}

Received: October 16, 2012 Accepted: November 19, 2012 Online Published: November 28, 2012

doi:10.5539/hes.v2n4p142 URL: http://dx.doi.org/10.5539/hes.v2n4p142

\begin{abstract}
Informatization, as a trend in the world's development nowadays, has become an important force to promote economic and social reforms. Since 1990s, information technology reforms have advanced dramatically. Along with the constant development of the information industry as well as the popularization of information network, informatization has been viewed as the dominant characteristics for the economic and social development of the whole world. New technologies have spread network entertainment by combining traditional entertainment forms and network. Young people, who value Internet a lot, have accepted network entertainment as an indispensable part in their life. Accordingly, any boycotting attitude toward their network entertainment may exert hindering influences on their development. As a result, it is quite necessary to have an overall understanding on college students' network entertainment activities and raise corresponding countermeasures so as to guide them to be positively affected and to achieve sound development as well. The questionnaire method is adopted in this research to investigate students from 9 classes of 3 different colleges of Changchun University of Science and Technology. Based on relevant data analysis, we put forward some countermeasures based on summarizing the effects of network entertainment.
\end{abstract}

Keywords: network entertainment, college students, influencing factors

\section{Definition and Characteristics}

Network entertainment, based on the computer and other electronic products which are attached to Internet, makes it possible for people to choose more leisure activities. From a subjective perspective, it is an emotional and psychological satisfaction; from an objective point of view, it can increase people's knowledge. The main difference between network entertainment and traditional entertainment is formally embodied in the entertainment forms. The notable feature of the former lies in the utilization of Internet. In addition, traditional entertainment forms such as singing, chatting, reading and so on are also included in network entertainment.

Network entertainment is based on the development in productivity which is brought by the revolution of information technology. It makes use of the computer and other electronic products to fuse traditional and modern entertainment forms. Different from the diversity of traditional entertainment forms, network entertainment is relatively unitary, involving mainly computers and other electronic subsidiaries.

Unlike traditional forms, network entertainment mainly relies on the Internet. Traditional entertainment generally involves individuals or groups who know each other well while network entertainment, covering a wider range, enjoys greater popularity and assembles more unfamiliar individuals and groups. Endowed with the general characteristics of network, network entertainment can realize real-time communication in many possible ways.

Due to its characteristics, network entertainment mainly involves reading, listening to music, chatting and other forms of mental relaxation instead of physical activities. Network Entertainment, relying on network technology, can have an important influence on young people. The key lies in that network entertainment is superior to traditional entertainment to some extent due to the characteristics of network. 


\section{Methodology of the Research}

The $29^{\text {th }}$ Statistics Report on Chinese Network Development, released by CNNIC (China Internet Network Information Center), suggests that online music, video and game constitute three most representative network entertainments, ranking the first six in all types of network entertainment, among which blog, microblog, social networking website and online literature are also included. Obviously network entertainment is the main activity of the college students.

Table 1. Service rate of specific network aplication from 2010 to 2011

\begin{tabular}{llllll}
\hline \multirow{2}{*}{ Application } & 2011 & 2010 & & & \\
& User Scale & Service Rate & User Scale & Service Rate & Annual Rate of Growth \\
\hline Instant Messaging & $415,100,000$ & $80.9 \%$ & $352,580,000$ & $77.1 \%$ & $17.7 \%$ \\
Search Engine & $407,400,000$ & $79.4 \%$ & $374,530,000$ & $81.9 \%$ & $8.8 \%$ \\
Online Music & $385,850,000$ & $75.2 \%$ & $362,180,000$ & $79.2 \%$ & $6.5 \%$ \\
Online News & $366,870,000$ & $71.5 \%$ & $353,040,000$ & $77.2 \%$ & $3.9 \%$ \\
Online Video & $325,310,000$ & $63.4 \%$ & $283,980,000$ & $62.1 \%$ & $14.6 \%$ \\
Online Game & $324,280,000$ & $63.2 \%$ & $304,100,000$ & $66.5 \%$ & $6.6 \%$ \\
Blog/Personal Space & $318,640,000$ & $62.1 \%$ & $294,500,000$ & $64.4 \%$ & $8.2 \%$ \\
Microblog & $249,880,000$ & $48.7 \%$ & $63,110,000$ & $13.8 \%$ & $296.0 \%$ \\
E-mail & $245,770,000$ & $47.9 \%$ & $249,690,000$ & $54.6 \%$ & $-1.6 \%$ \\
Social Networking Website & $244,240,000$ & $47.6 \%$ & $235,050,000$ & $51.4 \%$ & $3.9 \%$ \\
Online Literature & $202,670,000$ & $39.5 \%$ & $194,810,000$ & $42.6 \%$ & $4.0 \%$ \\
\hline
\end{tabular}

This research employs questionares which are issued to CUST current students. T-testing of the hpothesis testing is employed to analyze the network entertainment differences of the nine groups of students and how many differences exist. Combined with the mathmetical modeling, the influencing factors over network entertainment are comprehensively interpreted.

We adapt many ways to collecte concerned literatures dometically and abroad. Based on the college student entertainment development and the actual CUST students netwrok application, questions are posed and evaluated, thus questionares are designed. The second part of the questionares concerns the Network Entertainment Behaviour Study whereas the third part is about the College Mental Activity. Questionare utilizes Likert-tyPescale which adopts 5 points scale measurement.

The investigation is conducted among Science College, Economic Management College as well as Foreign Language College, selecting students from nine classes from Grade 1 to Grade 3 respectively. We issue 400 questionares in all, among which 382 questionares are retrieved and 364 questionares are valide, with 95.5 percent retrieving rate and 91 percent valid rate.

\section{The Analysis of the Influencing Factors}

\subsection{Dual Character of Network Entertainment}

Network entertainment is a double-edged sword, with some negative impacts on young people's physical, psychological and educational conditions. Young people excessively involved in network entertainment are not interested in physical development. Excessive time on online entertainment is potentially harmful. For example, when concentrating on the screen for a long time, eyes may be seriously hurt. If they cannot be relaxed enough, decreased vision, eye pain, photophobia, lacrimation and reduced adaptation to darkness may follow. In addition, many young people like snacks with low nutritional value and high calories when they are online. When they are playing games, they are in a state of high tension and keep a fixed position to control the mouse for a long time. Such a long-period fixed posture will lead to a disorder of their musculoskeletal systems. As a result, back pain, shoulder pain and distress may be caused. Furthermore, it can also cause serious spine injury, visceral oppression, or affect the functioning of heart and lungs. From the perspective of adolescents' mental health, unhealthy entertainment is not helpful for young people's psychological growth. The violent, terrorist and pornographic contents online directly affect young people's physical and mental health. According to Buchman and Funk's 
research, long-term immersion in violent games makes people prone to violence since violent games give them such an idea that the world is full of danger and they need to turn to aggressive or violent behaviors when solving problems. Therefore, when individuals are put in contact with too many violent games, they may show more aggressive behaviors. Finally, network entertainment has impacts on the cultural environment where young people stay in. It is easy to cause their confusion about the cultural environment and interpersonal roles. It also tends to lead to young students' psychological obstacles in dealing with interpersonal relationships.

Watching the impacts of network entertainment from different perspectives, you can find some features of such impacts. First, such impacts are exerted in diverse forms. Network entertainment almost involves all the contents of traditional entertainment like reading. Online you can not only find a variety of reading materials, but also some remarks and recommended books as well. It is safe to say that network entertainment does meet the diverse needs of adolescents, enhance young people's interest in it. Network entertainment provides an opportunity for young people to broaden their outlooks and enrich their knowledge. Second, advances in online search technology enable young people to find their preferable network entertainment contents quite easily. Online multimedia software achieves a combination of vision, hearing and reading. Therefore, entertainment becomes such enjoyment that young people tend to accept easily. Some newly-boomed technologies for network entertainment are attracting young people's attention to a greater extent, stimulating their curiosity and training their interest in such a mysterious and fascinating world. Third, network entertainment has very flexible requirements for space. You can enjoy it either by individuals, or you can join an online group for entertainment with others. It can involve both local groups and foreign ones. Such flexibility in entertainment space, of course, can promote increased opportunities for exchanges among young people, hence meeting the psychological needs of young people and expanding the awareness of the society.

Certainly, as for the nature of the impacts by network entertainment, it has both positive and negative influences. Its advantages are mainly manifested in the following aspects: network entertainment has provided a platform for young people. With network entertainment, young people's entertainment needs can be fulfilled and their stress can be relieved a lot. In addition, network entertainment is an important way to promote young people's socializing ability. Network entertainment forms a virtual platform for trials and errors, hence providing a buffer zone in adolescents' socialization process and setting a bridge over the transition period. Network entertainment has expanded channels for exchange, forming a new association represented by the digital entertainment space "virtual community". Network also exerts a positive impact in developing team spirits and enhancing cooperation. At the same time, network entertainment provides space for individual development among young people due to its broad participation. To a certain extent, it can promote young people's sense of participation in society. Role performance in network entertainment helps young people to develop the awareness of individuality and autonomy. Most of the network entertainment activities require participants to enter specific scenes and have role plays. During their participation, young people enter certain individual links accordingly. In addition, since network entertainment is closely linked with the latest technology, it can improve young people's awareness of innovation. Finally, the new technologies contained in network entertainment also have certain influences on young people's thinking.

\subsection{Impacts of Network Entertainment}

\subsubsection{Establishing New Entertainment Platform for Teenagers}

Online entertainment (online games, online community forums, online chatting, online movies, online television, online reading, etc.) has accounted for $41.3 \%$ of the entire entertainment components, $10 \%$ higher than sports, television and entertainment projects.

Our survey shows that $39.8 \%$ of the investigated young people think that network entertainment has a desirable relaxation effect with more technological means. Young people have access to diversified forms of entertainment online which also involve traditional media such as television, broadcast, music, chatting and so on. The survey also shows that $31.5 \%$ of the young people believe that network entertainment can satisfy their diversified demands. Obviously, with the development of network technology, network entertainment, embodying increasing and more colorful entertainment contents, has become an important carrier for young people's entertainment.

\subsubsection{Providing Young People with Important Socializing Channels}

First of all, network entertainment forms a virtual space tolerating trials and errors, hence a transitional channel for young people. Adolescents need a "buffer zone" in the socialization process, where teenagers can enjoy bearing more rights and fewer obligations at the same time. Accordingly, network entertainment can meet adolescents' demands better. Such a virtual environment gets rid of the commitment of "virtual responsibility" 
and therefore provides a bridge for transition.

Secondly, network entertainment has increased opportunities to practice by expanding communication channels. With the help of information technology, network entertainment provides young people with a new space "virtual community", in which they can achieve dimensional exchanges. It expands the range of adolescents' communication. In the virtual community, people establish close ties, and also extend friendship to the real life. Adolescents also can develop their understanding of the social rules in reality through their practice with the virtual social rules. The survey shows that $19.8 \%$ consider that network entertainment will improve their communication skills as well as broaden their scope of communication.

Besides, network entertainment is helpful to cooperative spirits. The only-child population in China has exceeded 100 million, forming a major issue nowadays. An investigation shows that $58.4 \%$ of the respondents feel that the only child is more willful and selfish. Some online entertainment forms, such as listening to music, forums and so on have an important feature, that is, to be based on group work. No matter in a real experience entertainment or a digital entertainment, groups formed due to mutual interest play an important role during the course. If young people want to participate in these groups, they have to be adapted to the group and the new environment. Many network entertainment activities require teamwork and therefore provide opportunities for young people to practice their teamwork spirits.

Finally, network entertainment gives adolescents self affirmation and confidence. To a certain extent, virtual roles in digital entertainment and the sense of achievements in entertainment can provide young people with confidence. Through network entertainment, they can achieve their own desires. What's more, this process is entirely based on their own decisions. This kind of self-confidence training can make teenagers integrate into the society faster. It is shown that $33.5 \%$ adolescents think the most important positive effect of network entertainment lies in enhancing their self-confidence.

\subsubsection{Providing Space for Young People's Individual Development}

First of all, network entertainment has a wide range of participation. To a certain extent, it can promote young people's awareness of social participation. Some entertainment activities also make young people fully practice social participation. These are more or less helpful to the enhancement of young people's awareness of participation, democratic awareness and the ability to participate. The survey shows that $22.5 \%$ of young people believe that network entertainment really helps to promote their awareness of social participation.

Second, vivid role playing in network entertainment is helpful to raise young people's individual consciousness and independence. Participants are asked to enter the entertainment scene and interact with each other, which helps to train young people's individual consciousness. It can make people to participate in the "role-establishing process". Young people in network entertainment may encounter a variety of difficulties, such as a failure in cooperation in online games, etc.). In this case, in order to overcome these difficulties and achieve the expected results, young people need to make adaptation to the role, create new behavior standards which this role does not have. This is an important part of young people's self-judgment and self-selection capability. The survey shows that nearly $10 \%$ of young people think that network entertainment is useful to display themselves and enhance their ability to act independently.

Once again, network entertainment is closely connected with the latest technology, hence helping to improve young people's cognitive level and to foster their sense of innovation. Modern network entertainment is based on intensive knowledge content, hence reflecting the development of modern science and technology. These high-tech entertainment products can attract the attention of young people to a large extent, stimulate their curiosity and develop their interest in the relevant field. Young people may learn about modern science and technology during their participation in network entertainment. It is possible to enhance young people's knowledge reserves and improve their innovative capabilities.

Finally, the application of new technologies in network entertainment will also have some impacts on young people's way of thinking, taking a further step that the Internet's self-organizing feature may change in its users' thinking. This applies to the development of young people's thinking and helps teenagers to improve their overall qualities. Flexible rules adopted in network entertainment are favorable for fostering young people's creativity and innovation. Due to strong randomness, participants have many options to obtain the desired results under the fair premises. As a result, participants would attach much importance to their imagination, which helps to cultivate their innovative ability. 


\section{Countermeasures for Improving College Students' Network Entertainment}

\subsection{Establishing a Concept for Scientific Development of Network Entertainment}

The remedy for teenagers' addiction to network entertainment involves systematic efforts. Government, school, family, relevant departments and the whole society should take on their responsibilities and have joint efforts to manage network culture and create a healthy and harmonious atmosphere. We should make good use of different organizations including the Communist Youth League, the Women's Federation, the Office of Youth Education at all levels, the committee for social groups and communities, village committees and other autonomous organizations and so on to realize all forces working jointly for young people's education and management. To extensively employ social forces, social assistance agencies should be paid attention to, such as the formation of communities, families, schools and politics and law departments. Besides, school education should play a major role. We should make full use of campus resources and guide students to use network technology scientifically. We should convert Internet into a good learning tool for both individuals and the society. Relevant discipline committees can be established to exercise students' self-education and self-management. We can also organize students to set up a network of civilization associations, through which more students are made self-disciplinary. At the same time, we should try our best to minimize and combat the negative effects of network entertainment so that students can get sound development in comprehensive quality.

\subsection{Strengthening the Construction of Infrastructure for Network Entertainment}

Investment should be increased in public education, sports, entertainment, leisure facilities and public service projects to create a wealth of recreational and cultural activities in order to prevent high school students from being addicted to the virtual world. Their demands for self -development can be fulfilled by developing their hobbies. At the same time, the poor situation of campus network environment should be improved to encourage young people to use the network at school.

Schools should take it as an important part of their routines to strengthen their facilities and carry out various activities actively, such as web design contests, writing network essays and reports and so on, to create a colorful campus culture atmosphere. While strengthening school education, we should also organize young people to participate in social practice so that they can improve themselves while they are helping others. We can use bulletin boards, youth cafes, new century book clubs and other youth activities to spread network knowledge and enlarge students' network knowledge. At the same time, it is of greater importance to strengthen the construction of network resources. With school web site being a main channel for teacher-student interaction, we should rely on it to carry out network cultural and educational activities. The interactivity, openness, timeliness of the network can be used to strengthen students' communication with teachers to make the network really involved in young people's study, work and life.

The government should support to establish some websites which are suitable for young people as soon as possible. At present, there are a limited number of sites suitable for young people. As a result, they can only turn to adult sites which are filled with a lot of improper information for them at their age. Therefore, a lot of parents and schools call for the establishment and perfection of special web sites which should be based on young people's physical and mental characteristics and interests. In this way, a scientific, informative and interesting world will be exposed to young people in our modern society.

\section{Conclusion}

For schools, they are expected to strengthen campus management, improve the construction of campus network and enrich campus life. Schools should carry out a wide range of activities for students to choose from. On one hand, such measures can reduce the opportunity for students to be absorbed in the net excessively; On the other hand, students' interests can be fostered and their pressure can be relieved. When perfecting the construction of campus network, we should not only meet their needs but also prevent the intrusion of unhealthy contents. Schools should work together with parents to strengthen supervision on students.

For parents, they should give their children more care. Family is an extremely important environment for students' growth. Parents should create a good family environment so that children can grow up healthily. When in need, parents are expected to offer their timely help.

For students, they should enhance self-control and cultivate their abilities to cope with difficulties. Students should improve their training, enhance self-control, and learn knowledge to enrich their lives. They should turn to other hobbies and entertainments to distract their attention from online temptations, hence relieving their pressure and improving their study as well. 


\section{References}

China Internet Network Information Center. (2012). The twenty-ninth statistical report on Internet development in China. Retrieved from http://www.cnnic.net.cn/hlwfzyj/hlwxzbg/201201/P020120709345264469680.pdf

Davis, R. A. (2001). A congnitive-behavior model of pathological internet use. Computers in Human Behavior. 17(2). http://dx.doi.org/10.1016/S0747-5632(00)00041-8

Davis, R. A., Flett, G. L., \& Besser. A. (2002). Validation of a New Scale for Measuring Problematic Internet Use: Implications for Pre-employment screening. CyberPsychology and Behavior, 5(4), 331-345. http://dx.doi.org/10.1089/109493102760275581

Lin, X. H. (2006). Phenomenon of Internet Addiction Research Overview. Chinese Journal of Clinical Psychology, 10(1), 74-76.

Shi, J. G. (2009). Addiction Medicine. Beijing: Science Press.

Whang, L. S., Lee, S., \& Chang, G. (2003). Internet over-users' psychological profiles: A behavior sampling analysis on internet addiction. CyberPsychology and Behavior, 6(2), 143-150. http://dx.doi.org/10.1089/109493103321640338

Wu, D. L. (2006). Harm and Countermeasure Analysis of Internet Addiction Disorder. Journal of Wenzhou Medical College, 8(4), 406-407. 